\title{
Bunge Brasil (1956 a 1994): consolidação de um grupo econômico *
}

\author{
Armando Dalla Costa ${ }^{* * * * *}$ \\ Gustavo Pereira da Silva * \\ Alexandre Macchione Saes ${ }^{* * * * *, * * * * * *}$
}

\section{Resumo}

Este artigo objetiva mostrar que a Bunge Brasil se consolidou como grupo econômico na segunda metade do século XX. Fundada em Amsterdam em 1818, atua no país desde 1905, chegando via Argentina onde estava presente desde o final do século XIX com o nome de Bunge y Born. Na década de 1990, o grupo Bunge Brasil chegou a ter 127 firmas independentes. Para este artigo selecionamos quatro delas, que representam diversos setores: trigo e moagem (Moinho Fluminense); tintas, vernizes e derivados (Tintas Coral); agronegócio e exportações (Sanbra); setor têxtil e confecções (Santista Têxtil). Teoricamente o texto segue os autores que discutem a formação de grupos econômicos em economias periféricas. Os dados primários foram levantados junto ao Centro de Memória Bunge, em São Paulo, e através de entrevistas. Como conclusão prévia pode-se afirmar que a Bunge se consolidou como grupo econômico na medida em que foi diversificando suas atividades e transformando algumas de suas 127 empresas em conglomerados industriais, elas mesmas tendo suas próprias coligadas e constituindo-se em outros grupos econômicos.

Palavras-chave: Bunge, Grupo econômico, Moinho Fluminense, Tintas Coral, Sanbra, Santista Têxtil.

\section{Abstract}

\section{Bunge Brasil (1956 to 1994): the consolidation of an economic group}

This paper aims to show that Bunge Brazil consolidated itself as an economic group in the second half of the twentieth century. Founded in Amsterdam in 1818, the company has operated in Brazil since 1905, arriving from Argentina where it had been present since the end of the 19th century under the name of Bunge and Born. In the 1990s, the Bunge Brazil group had 127 independent firms. For this study we selected four of them, representing several sectors: wheat and milling (Moinho Fluminense); paints, varnishes and derivatives (Coral Paints); agribusiness and exports (Sanbra); textile and clothing industry (Santista Têxtil). Theoretically the text analyzes the authors who discuss the formation of economic groups in peripheral economies. The primary data were collected from the Bunge Memory Center in São Paulo and through interviews. As a preliminary conclusion, it can be said

* Artigo recebido em 15 de maio de 2019 e aprovado em 15 de janeiro de 2020.

** Distinguished Visiting Scholar at the University of Illinois at Urbana-Champaign, USA (2020-2021). E-mail: ajdcosta@uol.com.br. ORCID: https://orcid.org/0000-0002-1016-7491.

${ }^{* * *}$ Bolsista de Produtividade em Pesquisa do Conselho Nacional de Desenvolvimento Científico e Tecnológico (CNPq), Brasília, DF, Brasil.

${ }^{* * * *}$ Professor do Departamento de Economia da Universidade Federal de São Carlos, Sorocaba, SP. Brasil. E-mail: gucamel2014@gmail.com. ORCID: https://orcid.org/0000-0003-0227-2643.

${ }^{* * * * * *}$ Professor do Departamento de Economia da Faculdade de Economia, Administração, Contabilidade e Atuária da Universidade de São Paulo (FEA/USP), São Paulo, SP, Brasil. E-mail: alexandre.saes@usp.br. ORCID: https://orcid.org/00000003-4274-1993.

****** Bolsista de Produtividade em Pesquisa do Conselho Nacional de Desenvolvimento Científico e Tecnológico (CNPq), Brasília, DF, Brasil. 
that Bunge has consolidated itself as an economic group while diversifying its activities and transforming some of its 127 companies into industrial conglomerates by having their own affiliates, and in turn forming other economic groups.

Keywords: Bunge, Economics groups, Moinho Fluminense, Tintas Coral, Sanbra, Santista Têxtil.

JEL N16, N56, N86.

\section{Introdução}

Em 1818, na cidade de Amsterdam, a Bunge \& Co. foi constituída por Johann Peter Bunge com vistas ao comércio de madeiras, especiarias, algodão, borracha e outros produtos das colônias holandesas. Em 1859, já comandada por Eduardo Bunge - neto de Johann Peter mudou sua sede para Antuérpia (Bélgica) e agregou a atividade de importação de grãos. Em 1884, Ernesto Bunge, irmão de Eduardo que havia migrado à Argentina em 1876, associou-se a outro comerciante vindo de Antuérpia, seu cunhado Jorge Born, e formou a Bunge y Born, exportadora de cereais e subsidiária da Bunge europeia. Em 1897, Alfredo Hirsch e Jorge Oster, dois comerciantes de origem alemã, associaram-se a Ernesto Bunge e Jorge Born, capitalização que contribuiu para a Bunge tornar-se uma das maiores exportadoras de trigo argentino no final do século XIX (Green; Laurent, 1989, p. 17-28; Barbero, 2011; Bunge Relatório, 2017) ${ }^{1}$.

A expansão econômica da Argentina, país de maior PIB per capita na América Latina (US\$ 4.557,00) e com a maior taxa de crescimento do PIB (média de 5,8\% ao ano) entre 18701913, teve na exportação de grãos uma importante atividade, sobretudo o trigo e o milho, visto que, desde 1880 formara-se um setor de produção e exportação de grãos. O trigo era produzido no interior e levado para moagem em Buenos Aires e Rosário, de onde a farinha era exportada para poucos países, como o Brasil. De outra parte, o trigo in natura argentino atendia aos países europeus e os Estados Unidos. O controle sobre a exportação de cereais - além da participação no setor financeiro e imobiliário - possibilitou à Bunge y Born posicionar-se como o maior grupo familiar da Argentina nos anos 1920, período em que já havia iniciado seu processo de internacionalização junto aos países latino-americanos (Fausto; Devoto, 2004, p. 165; Ocampo; Bértola, 2012, p. 97; Green; Laurent, 1989; Barbero, 2011, p. 15, Dalla Costa; Silva, 2018).

Atenta às possibilidades geradas pelo atendimento à demanda brasileira de farinha de trigo, a Bunge y Born iniciou suas atividades no Brasil em 1905, ao associar-se ao Moinho Santista - adquiriu $10 \%$ do capital desta empresa moageira ${ }^{2}$. A participação da Bunge na economia brasileira foi se ampliando no decorrer do século XX e, nos anos 1990, o grupo contava com 127 empresas, em ramos tão diferentes quanto financeiro, agronegócio, tintas, cimento, fosfato, adubos, têxteis, fábrica de salames, trigo e derivados, sorvetes, cinema, exportações. Segundo o Handbook of Business Groups, em 2007, a Bunge era o $14^{\circ}$ maior grupo econômico brasileiro - com receita líquida de US\$ 12 bilhões de dólares - sendo que,

(1) A exportação de trigo na economia argentina estava concentrada nas mãos de fortes grupos exportadores, os chamados "quatro grandes": Bunge y Born, Huni y Wormser, Dreyfus e Weil Brothers (Fausto; Devoto, 2004, p. 165-167).

(2) A produção brasileira de farinha de trigo supria aproximadamente 50,9\% do consumo total em 1903, cifra que aumentou para 57,5\% em 1909 (Suzigan, 2000, p. 207). 
no setor alimentício, era superada apenas pela Companhia de Bebidas das Américas (Ambev) (Documentos do Centro de Memória Bunge e Netz, 1993; Calais, 2017; Dalla Costa; Silva, 2018, p. 202, Suzigan; Szmrecsányi, 2002, p. 236; Aldrighi; Postali, 2010, p. 355-357).

Atualmente, a Bunge Brasil é uma subsidiária da Bunge Limited, posto que a sede do grupo foi transferida da cidade de São Paulo - onde estava desde 1975 -, em 1999, para White Plains (Estados Unidos)3․ A Bunge Brasil atua em três áreas: agronegócio; alimentos \& ingredientes; açúcar \& bioenergia. São mais de 100 instalações, entre fábricas, usinas, moinhos, portos, centros de distribuição e silos, em 17 estados, além do Distrito Federal. Ao fim de 2015, a Bunge contava com 15.678 funcionários, teve uma receita de $\mathrm{R} \$ 39,7$ bilhões e um lucro de $\mathrm{R}$ \$ 1,5 bilhão. Com isso, a Bunge Brasil representou 38\% dos ativos globais, o que demonstra a importância de suas operações no país (R.S., 2016, p. G-9).

Alguns trabalhos buscaram traçar um panorama geral sobre a formação de grupos econômicos no Brasil (Gonçalves, 1991; Bonelli, 1998; Gonçalves, 1999; Minella, 2006; Rocha, 2013; Aldrighi; Postali, 2010; Dalla Costa; Drumond; Las Heras, 2015; Trindade, 2017). Todavia, permanece uma lacuna em relação aos estudos de caso, justamente para confrontar as hipóteses levantadas por estes trabalhos com o evolver dos grupos econômicos no Brasil. Sobre a Bunge, evidenciamos que há uma boa bibliografia sobre sua atuação na Europa e Argentina ${ }^{4}$, ao passo que, em relação à Bunge Brasil, encontramos duas análises que nos ajudam a definir o recorte do trabalho ora proposto. A primeira é de Dalla Costa e Silva (2018) que recobre o período 1905-1955, temporalidade encarada como de introdução e adaptação da Bunge ao mercado brasileiro. A segunda é de Serra, Ferreira e Contrigiane (2009) que mostram a evolução da Bunge após 1994, com foco em seu processo de reestruturação marcado pela diminuição das empresas coligadas.

Dessa forma, o objetivo do texto é mostrar como a Bunge consolidou-se num grupo econômico diversificado no mercado brasileiro na segunda metade do século XX, iniciando a análise a partir de 1956 - período que não foi coberto por Dalla Costa e Silva (2018) - e finalizando no ano de 1994 em que, após um processo de reestruturação, as 127 firmas da Bunge Brasil foram reduzidas a apenas 30. O trabalho selecionou quatro empresas do Grupo, que eram as mais importantes considerando o faturamento, o número de empregados conforme a Tabela 1 - e, sobretudo, por funcionarem como holdings que lideravam as demais empresas dos seus respectivos setores através da participação acionária: Moinho Fluminense (trigo, farinhas e outros derivados), Tintas Coral (tintas, vernizes e derivados), Sociedade Algodoeira do Nordeste Brasileiro/Sanbra (agronegócio e exportações) e; por fim, a Santista Têxtil (setor têxtil e confecções) para mostrar seu desenvolvimento.

(3) Desde 2013, o Grupo Bunge possui uma estrutura piramidal que se organiza da seguinte maneira (nome da empresa, localização, função no grupo): Bunge Limited, White Plains (Estados Unidos), controladora/holding; Bunge Brasil, cidade de São Paulo (Brasil), Subsidiária; Bunge Cone Sul, Buenos Aires (Argentina), Subsidiária; Bunge Ásia, Singapura, Subsidiária; Bunge Europa, Oriente Médio \& África, Genebra (Suíça), Subsidiária; Bunge Global Agronegócio, White Plains (Estados Unidos), Subsidiária; Bunge América do Norte, Saint Louis (Estados Unidos), Subsidiária (Relatório, 2013).

(4) Green e Laurent (1985), Schvarzer (1989), Barbero (2013), Barbero e Lluch (2015) e Cuesta e Newland (2016). 
Tabela 1

Bunge Brasil: Áreas de Atuação e Empresas líderes - 1993

\begin{tabular}{l|c|c|c}
\hline Empresas & $\begin{array}{c}\text { Faturamento } \\
\text { (em US\$ } \\
\text { Milhões) }\end{array}$ & Funcionários & $\begin{array}{c}\text { Principais } \\
\text { Marcas }\end{array}$ \\
\hline Tintas Coral (Tintas) & 283 & 1.962 & Coralatex, Coralplus, Coralmur, Coralit \\
\hline Tatuapé (Têxtil) & 449 & 8.900 & Santista, Solasol, Tapé, Indigo \\
\hline $\begin{array}{l}\text { Sanbra/Samrig (óleo } \\
\text { de soja e margarinas) }\end{array}$ & 703 & 4.182 & $\begin{array}{c}\text { Delícia, Mila, Primor, Salada, } \\
\text { Maionegg's }\end{array}$ \\
\hline $\begin{array}{l}\text { Santista Alimentos } \\
\text { trigo e derivados) }\end{array}$ & 344 & 2.661 & $\begin{array}{c}\text { Boa Sorte, Sol, Loirinha (farinhas); } \\
\text { Petybon, Favorita (massas); Avevita, } \\
\text { Avesano (rações) }\end{array}$ \\
\hline $\begin{array}{l}\text { Serrana (Cimento e } \\
\text { Fosfatados) }\end{array}$ & 127 & 1.039 & $\begin{array}{c}\text { Cimento Serrana, Cimento Bagé, } \\
\text { Foscálcio Serrana e Argamassa Serrana }\end{array}$ \\
\hline Total & 1.906 & 18.474 & \\
\hline Fonte: Elaboração dos autores a partir de Netz (1993, p. 22).
\end{tabular}

Para tanto, o artigo se embasa em fontes primárias arroladas junto Centro de Memória Bunge: atas de reuniões dos conselhos administrativos das empresas do Grupo, Relatórios Anuais, Estatutos, e Demonstração Contábeis e Publicações Internas ${ }^{5}$. O trabalho inicia com uma discussão de aspectos teóricos sobre formação de grupos econômicos em países emergentes a fim de enquadrar a atuação da Bunge no país. Em seguida, aborda-se as quatro empresas do Grupo listadas acima e a presença em seus respectivos setores. Por fim, concluímos com os apontamentos mais significativos.

\section{A Bunge e a formação de grupos econômicos em economias periféricas}

A organização das empresas enquanto Business Groups/Grupos Econômicos doravante $\mathrm{BG}$ - não diz respeito a um fenômeno recente, tampouco está restrito às economias relativamente atrasadas. Os primeiros Grupos - as companhias comerciais britânicas - teriam surgido na Inglaterra no início do século XIX, em meio ao espocar da Revolução Industrial, e entre 1850-1913, em países da Europa Continental (Suécia, França, Itália, Rússia, Alemanha e outros), bem como nos Estados Unidos, onde era comum encontrar estes BG (Colpan; Hikino, 2016, p. 11-12; Jones; Colpan, 2010, p. 71; Holmes Jr. et al., 2018).

Em que pese haver divergências acerca do conceito de Business Groups (BG), utilizaremos a definição de Khanna e Yafeh (2007, p. 331): "Esses grupos normalmente compostos de empresas juridicamente independentes, que operam em várias indústrias (muitas vezes não relacionadas), que são ligados entre si por persistentes laços formais (por exemplo, patrimônio) e informais (por exemplo, família) ". A escolha se deve ao fato desta definição ser

(5) Os autores, através da Cláudia Calais, Ana Isabel Ferraz e Viviane Morais agradecem a toda a equipe do Centro de Memória Bunge (cidade de São Paulo, Brasil), tanto pelo acesso à documentação, como pelo suporte na pesquisa. 
amplamente utilizada por trabalhos recentes e, também, por abarcar os três aspectos centrais dos BG: presença de famílias no controle dos Grupos; diversificação produtiva nãorelacionada, ou seja, que não se restringe às atividades centrais (core business); e a existência de subsidiárias independentes - as empresas coligadas - que compõem o Grupo e são atores importantes para a diversificação das atividades (Colpan; Hikino, 2016; Barbero, 2011; Colpan; Hikino, 2010; Carney et al., 2011; Bull, 2013; Yaprak; Karademir, 2010; Koury, 2011; Yildirim-Öktem; Selekler-Goksen, 2018).

Em relação às nações economicamente emergentes, os BG apareceram como estrutura empresarial no começo e decorrer do século XX, tendo relevante papel no processo de industrialização de países como Brasil, Argentina, Chile, Coreia do Sul, China, Índia, México e outros (Colpan; Hikino; Lincoln, 2010; Carney et al., 2017). Nestas nações de mercados institucionalmente em formação - como proposto por Khanna e Palepu (1997), Khanna e Yafeh (2007) e originalmente por Leff (1974) - um elemento comum seria a presença de vácuos institucionais: reduzida oferta de capital aos novos investimentos, dificuldade no acesso às matérias-primas e/ou fontes energéticas, problemas de escoamento da produção, baixa oferta de trabalho qualificado.

No caso da economia brasileira, estes vácuos institucionais são latentes ao final da década de 1920. Apesar da superação do marasmo econômico vivido na segunda metade do século XIX - o crescimento médio anual do PIB per capita foi de 0,4\% entre 1850-1889 e, entre 1889-1930, foi de 0,9\% - o Brasil permanecia uma nação atrasada socioeconomicamente em relação aos países latino-americanos ${ }^{6}$. Este atraso era característico de uma economia primário-exportadora altamente concentrada, em que a agricultura respondia por $36 \%$ do PIB nacional - enquanto a indústria representava $15 \%$ - e a dinâmica era dada pelo setor exportador, onde o café respondia por mais de 70\% da pauta (Franco; Lago, 2012; Villela, 2013; Villela, 2018).

Os vácuos da pouco industrializada economia do Brasil ao final dos anos 1920 podem ser evidenciados em alguns aspectos. Apesar de ter construído 32 mil quilômetros de ferrovias até 1930 - a Argentina tinha 38 mil quilômetros de ferrovias no mesmo ano - pode-se considerar que esta malha era pouco integrada e gerava problemas para a chegada de insumos e escoamento da produção, demonstrado pela falta de açúcar que ocorreu no estado de São Paulo nos anos da II Guerra Mundial, devido à interrupção da navegação de cabotagem, uma vez que os estados do Nordeste atendiam a demanda paulista (Bértola; Ocampo, 2012, p. 95; Szmrecsányi, 1976; Franco; Lago, 2012).

Os BG surgem como respostas a estas falhas de mercado. A organização destes grupos, segundo Colpan e Hikino (2010, p. 16), deu-se pela escolha de uma estrutura de propriedade

(6) Em 1929, o PIB per capita da Argentina era 4 vezes maior que o do Brasil, o do Chile era 3 vezes maior, além de representar apenas 66\% do PIB da Colômbia e 62\% do PIB do México. Na Argentina e no Chile 75\% da população era alfabetizada no ano de 1930, na Colômbia 52\% da população, enquanto no Brasil somente 40\% (Bértola; Ocampo, 2012, p. 113, 293). 
piramidal, em que no vértice encontra-se uma empresa central (holding) - podendo ser uma família a controlá-la - a liderar as subsidiárias independentes que atuam em setores cuja produção tende a ser não-relacionada, ou seja, há uma propensão dos grupos econômicos à diversificação produtiva ${ }^{7}$. Estas famílias empresárias - no caso da Bunge os membros são Bunge, Born, Hirsch e Oster - exercem o controle das empresas alocando seus membros nos cargos de direção, possuindo a maioria das ações ou mesmo induzindo as firmas do Grupo a financiarem os investimentos e a formação das subsidiárias, direcionando os rumos da diversificação produtiva (Fernández Pérez; Lluch, 2015, p. 18-19; Fernández Pérez; Casanova, 2012, p. 281).

As vantagens geradas por este modelo de organização empresarial baseiam-se nas constantes trocas de informações, recursos produtivos, capacidade laboral e capital entre a controladora e as subsidiárias (Guillén, 2000; Khanna; Palepu, 1997; Keister, 1998). Estas características dos grupos econômicos lhes permitem: atuar em diversos setores; obter economias de escala e escopo através da melhor utilização de recursos internos; maior poder de mercado; diminuição de riscos; ganhos de aprendizado; além de maiores fontes de capitalização do grupo através dos lucros de suas subsidiárias - compensando prejuízos com outras empresas do grupo (Granovetter, 2005, Morck, 2010, p. 609; Delios; Ma, 2010, p. 721; Khanna; Yafeh, 2007, p. 579).

No caso do Brasil, estes pressupostos dos BG são evidentes. As famílias aparecem como controladoras da maioria dos BG - que são estruturas piramidais - a atuar no mercado nacional; grande parte destes Grupos são diversificados, pois atuam em, ao menos, três ramos industriais, sendo esta diversificação uma resposta às falhas de mercado (Aldrighi; Postali, 2010, p. 371). O elevado peso destas grandes estruturas empresariais lhes possibilita um importante poder de barganha, quando estes BG se alinham às políticas de desenvolvimento das nações emergentes, cenário que se deu a partir de 1930 no caso brasileiro, quando o Governo Federal comandou o processo de industrialização (state-led industrialization) valendo-se da entrada de BG estrangeiros e da formação de nacionais, corroborando para uma relação positiva entre a performance dos BG e a eliminação dos vácuos institucionais (Carney et al., 2011, p. 452; Schneider, 2010, p. 662; Guillén, 2000, p. 366; Ocampo; Ros, 2011, p. 414).

A Bunge foi um dos principais BG que passou a atuar na economia brasileira no século XX. Na sequência, o artigo analisa quatro empresas individuais dentro da Bunge, líderes em seus setores de atividade, que contribuíram para sua consolidação como grupo econômico. Representavam os setores de moinhos de trigo, farinhas e demais derivados (Moinho Fluminense); tintas, corantes e pinturas (Tintas Coral); algodão, exportações e alimentos

(7) Morck (2010, p. 609) diz que a existência de empresas subsidiárias - que são juridicamente independentes - vinculadas a uma empresa-mãe (holding) é o que diferencia os grupos econômicos dos conglomerados, estes sendo as grandes empresas integradas verticalmente analisadas por Chandler (1962). 
(Sanbra); tecidos, jeans e têxteis em geral (Santista Têxtil). Através delas demonstraremos o passo a passo da consolidação de um grupo econômico.

\section{Moinho Fluminense e o setor de trigo e derivados da Bunge}

A Tabela 1 apresenta como uma das empresas do Grupo Bunge no Brasil, a Santista Alimentos, adquiriu tamanho para se tornar, ela própria, um grupo econômico. Na verdade, tratou-se da reunião das empresas do Grupo que lidavam com trigo e derivados, sendo a principal, o Moinho Fluminense.

Inaugurado em 1887, quando recebeu a autorização da Princesa Isabel, o Moinho Fluminense nasceu da iniciativa de Carlos Gianelli - que vinha de uma família de moageiros de trigo no Uruguai - e do empresário do ramo têxtil e ferroviário, Francisco de Paula Mayrink - além de outros acionistas (CMB, 2016, p. 9; Contrato Social, 1887, p. 12). Em 1907, o Moinho Fluminense era o segundo maior do Brasil, considerando a capacidade produtiva, e dividia o domínio do mercado do Rio de Janeiro (capital do Brasil) com a firma britânica The Rio de Janeiro Flour Mills \& Granaries Ltda. (Suzigan, 2000, p. 206).

A demanda por trigo, fosse em grão ou farinha, estava em expansão no Brasil e, mesmo com avanços na capacidade moageira nacional, em 1913-1914, o Brasil ainda importava 34\% da farinha de trigo consumida, fazendo deste abastecimento um importante negócio, sobretudo aos grupos internacionais que comandavam a cadeia do trigo na América do Sul (Suzigan, 2000, p. 207; Green; Laurent, 1989). A Bunge, por meio da subsidiária argentina (Bunge y Born), já se atentara a esta oportunidade e ingressou no mercado brasileiro desde 1905, quando adquiriu 10\% das ações do Moinho Santista, segundo maior moinho do estado de São Paulo e localizado na cidade de Santos (Dalla Costa; Silva, 2018, p. 202).

Na busca de maior controle da cadeia cerealífera no continente, a Bunge y Born tomou a decisão de comprar o Moinho Fluminense. Conforme indicado por Fernández Pérez e Casanova (2012) e Fernández Pérez e Lluch (2015), a efetivação da compra se daria por meio do domínio de 48,92\% das ações da empresa por parte do BG Bunge e, também, pela posição estratégica dos membros da família nos postos de comando, pois no Conselho Administrativo do Moinho Fluminense ${ }^{8}$ aparecem, com a maior quantidade de votos: Alfredo Hirsch e Mauricio Bunge com os mesmos 1.469 votos cada um, Conrado Jacob de Niemeyer 1.449, Comendador Luiz Camuyrano 1.460, David Roberts 1.269 e Leopoldo Gianelli 229, segundo a Tabela 2.

(8) Ata da Reunião Extraordinária do Moinho Fluminense, 28 de maio de 1914, p. 16. 
Tabela 2

Moinho Fluminense - Acionistas - 1929

\begin{tabular}{l|c|c}
\hline Acionistas & Total de ações & $\%$ \\
\hline Bunge y Born Ltd. (Buenos Aires) & 87 & 0,48 \\
\hline Bunge \& Cia. (Londres) & 8.806 & 48,92 \\
\hline Horácio Gianelli & 3.110 & 17,27 \\
\hline Viúva Roberts & 612 & 3,40 \\
\hline Bank of London & 500 & 2,77 \\
\hline Banco Italo Belga & 305 & 1,69 \\
\hline Viúva Camuyrano & 60 & 0,33 \\
\hline Outros & 4.520 & 25,11 \\
\hline Total & 18.000 & 100,00 \\
\hline
\end{tabular}

Fonte: Elaboração dos autores a partir de Moinho Fluminense S/A. Acionistas 19/03/1929.

A Tabela 2 aponta, como indicado por Guillén (2000) e Morck (2010), a facilidade na mobilização de recursos financeiros por parte dos BG. A capitalização proporcionada pela Bunge \& Cia. (holding do BG situada em Londres) permitiu à subsidiária argentina aumentar sua participação em um importante mercado, mas com problemas institucionais - como a escassez de crédito de longo prazo - que poderia ter inviabilizado tal empreendimento. De outra parte, a compra do Moinho Fluminense representava um aprofundamento da Bunge em seu core business, ou seja, o controle sobre a cadeia de cereais a nível mundial (Barbero, 2011).

O Moinho Fluminense consolidou-se como uma das principais empresas do ramo moageiro no Brasil. Em 1949, as novas instalações do Moinho Central (localizadas em São Paulo) seriam inauguradas, com capacidade de moagem de 450 toneladas diárias. No mesmo ano, o Moinho Fluminense, em seus estabelecimentos do Rio de Janeiro, iniciou a fabricação de rações balanceadas, para gado e aves (M.F., 1927/1957, p. 30).

Na década de 1950 continuaria sua ampliação e diversificação. Em 1956, ele terminou a construção de novos silos e entrou em funcionamento, no Moinho Central de São Paulo, uma fábrica de massas alimentícias (M.F., 1927/1957, p. 30). Em 1968, o Moinho Fluminense S. A. Indústrias Gerais tinha as seguintes indústrias: moinho de trigo (Rio de Janeiro e Barra Mansa); fábrica de rações balanceadas (Rio de Janeiro); fábrica de massas alimentícias (São Paulo); degerminação de milho (Rio de Janeiro). Contava com filiais em: Belo Horizonte, Juiz de Fora, Petrópolis, Niterói, Campos. Tinha agências em: Vitória, Três Rios, Campos, Além Paraíba e sua sede estava no Rio de Janeiro (R.A. 1968-1969, p. 2). Após expansão da capacidade instalada de suas plantas industriais, no biênio 1971-72 a unidade do Moinho Fluminense do Rio de Janeiro, isoladamente, industrializava e vendia a maior quantidade de trigo do país (M.F., 1927/1957, p. 32) .

(9) O Moinho Fluminense inicia a década de 1970 como o maior do Hemisfério Sul do planeta. Ele respondia por $48 \%$ do abastecimento de farinhas à população do Estado do Rio de Janeiro e por 64\% da capital (Histórico, p. 10). 
A bem-sucedida trajetória do Moinho Fluminense na década de 1970 permitiu fazer desta subsidiária da Bunge um instrumento para transferir capital às outras afiliadas e diversificar as atividades do Grupo no Brasil para ramos que iam além da cerealífera (diversificação não-relacionada), uma das vantagens imputadas aos BG por Khanna e Yafhe (2007) e Morck (2010) e Delios e Ma (2010) ${ }^{10}$.

Tabela 3

Moinho Fluminense - Empresas onde investe capital - 1975-76

\begin{tabular}{l|c|c|c}
\hline Empresa & $\begin{array}{c}\text { Capital (em Cr\$ } \\
1.000)\end{array}$ & $\begin{array}{c}\text { Participação } \\
\text { (em Cr\$ 1.000) }\end{array}$ & \% do capital \\
\hline 1. Fábrica de Tecidos Tatuapé S.A. & 270.000 & 109.564 & 40,58 \\
\hline 2. S.A. Moinhos Riograndenses & 219.700 & 84.619 & 38,51 \\
\hline 3. Grandes Moinhos do Brasil S.A Indústrias Gerais & 122.000 & 42.964 & 25,24 \\
\hline 4. Quimbrasil - Química Industrial Brasileira S.A. & 260.000 & 31.419 & 9,79 \\
\hline 5. Santista Indústria Têxtil do Nordeste S.A. & 141.643 & 21.642 & 15,28 \\
\hline 6. Toalia S.A. Indústria Têxtil & 75.842 & 15.598 & 20,14 \\
\hline 7. Lubeca S.A. Administração e Leasing & 145.000 & 15.512 & 10,70 \\
\hline 8. Banco Francês e Brasileiro S.A. & 160.000 & 10.924 & 6,82 \\
\hline 9. Proceda - Serviços Administrativos S-C & 20.000 & 3.000 & 15,00 \\
\hline 10. Vera Cruz Seguradora S.A. & 30.000 & 3.148 & 9,36 \\
\hline 11. Serrana S.A. de Mineração & 111.000 & 2.823 & 2,00 \\
\hline 12. S.A. Moinho Santista Indústrias Gerais & 412.500 & 1.557 & 0,38 \\
\hline 13. Cia. Siderúrgica Nacional & 2.800 .593 & 426 & - \\
\hline 14. Sanbra S.A. Agropecuária e Industrial & 1.500 & 300 & 20,00 \\
\hline 15. Embraer - Empresa Brasileira de Aeronáutica & 193.719 & 99 & - \\
\hline 16. Outras & - & 43 & - \\
\hline Fon & & $9,1975-76$. & \\
\hline
\end{tabular}

Fonte: Elaboração dos autores a partir de Moinho Fluminense. Relatório Anual, p. 8, 1975-76.

A Tabela 3 mostra que os investimentos do Moinho Fluminense concentraram-se nas empresas do Grupo Bunge - exceto pelas estatais Embraer e a Cia. Siderúrgica Nacional - e, principalmente, destaca-se a diversidade de setores, desde roupas e tecidos; moagem de trigo e derivados; química; leasing e administração de bens; bancos; serviços administrativos; seguros; mineração e adubos; siderurgia; agropecuária, agronegócio; e aviação. Esta união de interesses entre a holding (Bunge Brasil) e as afiliadas será elemento fundamental para que o BG Bunge chegasse a ter 127 empresas coligadas no mercado brasileiro ao início da década de 1990, sendo uma delas a Tintas Coral.

(10) O core business do Grupo Bunge na América do Sul era a moagem e exportação de cereais, tanto que, nos anos 1970, o maior BG da Argentina era a Bunge y Born, sendo sua principal empresa os Molinos Río de La Plata (Barbero; Lluch, 2015, p. 254). 


\section{Tintas Coral}

Em 1954, a Bunge era o principal BG na Argentina e seu principal empreendimento era a Alba, criada em 1925 e que foi a primeira fábrica de tintas da América do Sul (Barbero; Lluch, 2015, p. 251). A expertise adquirida no setor químico, os capitais acumulados e os recursos profissionais formados nestas décadas de domínio no mercado argentino foram acionados pelo BG para iniciar esta atividade no mercado brasileiro, constituindo estas capacidades em ativos importantes que diferenciam os BG, conforme Granovetter (2005), Khanna e Palepu (1997) e Carney et al. (2011).

A Tintas Coral foi criada pela Bunge y Born como Companhia Lubeca, em 1954. Para tanto, os primeiros executivos foram selecionados entre os funcionários de outras empresas da Bunge Brasil, como o Moinho Santista, enquanto que o arcabouço tecnológico e científico foi garantido pelos químicos e técnicos da Alba oriundos da Argentina e de brasileiros que estagiaram na Alba por até um ano (CMB, 1986, p. 1).

A Tabela 4 indica que, em meados da década de 1960, os principais acionistas da Tintas Coral Nordeste eram outras firmas pertencentes ao grupo Bunge (Sanbra, Grandes Moinhos do Brasil e Tintas Coral S. A.), uma das características que ajudava a consolidar o grupo econômico Bunge, já mostrada, anteriormente, em relação ao Moinho Fluminense (Tabela 4).

Tabela 4

Tintas Coral Nordeste - Acionistas - 1965 (em Cr\$ mil)

\begin{tabular}{l|c|c}
\hline Pessoa física ou jurídica & Domicílio/sede & Capital \\
\hline Sanbra - Sociedade Algodoeira do Nordeste Brasileiro & São Paulo & 1.400 .000 \\
\hline Grandes Moinhos do Brasil S.A. & Pernambuco & 500.000 \\
\hline Tintas Coral S.A. & São Paulo & 999.950 \\
\hline Elemer Janovitz & Recife & 10 \\
\hline Otto Richard Georg Hinrichsen & Recife & 10 \\
\hline José Carlos Fernandez & São Paulo & 10 \\
\hline Ernest Engel & Recife & 10 \\
\hline Luiz Fernando Guedes Pereira & Recife & 10 \\
\hline Grupo Líder e terceiros & & 2.900 .000 \\
\hline
\end{tabular}

Fonte: Elaboração dos autores a partir de Tintas Coral (1965, p. 7).

A empresa iniciou suas atividades em 20 de dezembro de 1954, com a inauguração da fábrica de Santo André, SP. A produção inicial era de 300 mil litros/ano de tintas a óleo. Com o crescimento do mercado, ampliou seus negócios: em 1968 criou a unidade do Recife-PE, a Tintas Coral do Nordeste; em 1976 construiu a planta industrial de Mauá-SP; em 1989 definiu a joint-venture Hempel/Coral e, em 1994, inaugurou a Pinturas Coral de Bolívia, em Santa 
Cruz de la Sierra, transformando-se de uma subsidiária em outra multinacional, com planta industrial no estrangeiro (Tintas Coral, 1994, p. 2) ${ }^{11}$.

Em 1994, além de atuar no setor de tintas no Brasil, a Bunge tinha plantas industriais em outros três países latino-americanos: Uruguai (Inca), Argentina (Alba) e Bolívia (Coral Bolívia), caracterizando a Coral do Brasil como um dos braços do setor de tintas da Bunge (Bunge Paints, 1994). Sobre a participação no mercado brasileiro, em princípios da década de 1990, a Coral mantinha 26\% (segundo lugar), de um mercado de US\$ 1,6 bilhão; a Alba era líder na Argentina, com 42\% de um mercado de US\$ 530 milhões; a Inca era líder no Uruguai, com 70\% de um mercado de US\$ 60 milhões (Bunge Paints, 1994).

Uma das consequências da reestruturação do grupo Bunge, focando-se no agronegócio e alimentos, foi a venda dos demais setores em que atuava. No caso da Tintas Coral, o comprador foi o grupo britânico Imperial Chemical Industries (ICI) que adquiriu, em 1996, as operações de tintas do Grupo Bunge. Com esta compra, a ICI se lançou no mercado latinoamericano. As negociações incluíram as empresas Tintas Coral, do Brasil - e suas subsidiárias Alba S.A., da Argentina e Pinturas Inca S.A., do Uruguai, que faziam parte da Bunge Paints divisão de indústrias de tintas do Grupo Bunge para o Mercosul. Com a compra, surgiu uma nova empresa a ICI Paints Mercosul com fábricas no Brasil, Argentina e Uruguai (CMB, 2010, p. 13; Born, 2008).

\section{Sanbra consolida Bunge no setor agropecuário e exportador}

A Sanbra: Sociedade Algodoeira do Nordeste Brasileiro S.A. surgiu, em 1919 no Recife, como firma Cavalcanti \& Cia. Em seguida, a Bunge adquiriu a empresa Cavalcanti \& Cia. que, em 1923, mudou seu nome para Sanbra, tornando-se a primeira empresa da Bunge Brasil no segmento de oleaginosas ${ }^{12}$. Naquele momento, o caroço de algodão passou a ser usado para fins alimentares, através da extração e do refino do óleo ${ }^{13}$.

Deve-se pontuar que, contemporaneamente, a Bunge y Born (subsidiária na Argentina) tinha como uma de suas empresas o Molinos Río de La Plata - 2a maior empresa daquele país em 1937 - e que também atuava no segmento de oleaginosas, mas processando sementes de girassol e ofertando uma variedade de bens de consumo (margarinas, óleos vegetais, maionese e outros), indicando que, tanto na Argentina quanto no Brasil, as subsidiárias permitiam à Bunge empreender uma diversificação não-relacionada ao setor de cereais - criar domínio em

(11) O mercado brasileiro de tintas tinha uma produção anual de 627 milhões de litros/ano (77,8\% na linha imobiliária; 16,7\% na industrial e 5,5\% na de repintura automotiva), com faturamento de US\$ 1,6 bilhão. Em 1994 a Coral tinha 26\% do mercado da linha imobiliária; $15 \%$ na de repintura automotiva e $13 \%$ na industrial. A Tintas Coral era a segunda empresa do setor, liderando em várias regiões do Brasil e exportando para 20 países (Tintas Coral, 1994, p. 2).

(12) http://www.bunge.com.br/Bunge/Nossa Historia.aspx. Acesso em: 11 jan. 2016

(13) Os dados a respeito do histórico da Sanbra foram consultados em diferentes materiais no Centro de Memória Bunge em São Paulo. As informações das atividades no Recife encontram-se em SANBRA 50 anos. Separata de Atualidades Sanbra, n. 31. Ano 6, jan./fev.1973 - História do Algodão. Publicada pela Coordenação de Relações Públicas da Sanbra, p. 12 e seguintes. 
novos setores - vantagem apontada por Morck (2010) e Delios e Ma (2010) e semelhante ao caso das Tintas Coral.

A Sanbra instalou-se em 1935/36 na cidade de Campina Grande, na Paraíba, com um escritório de compra de algodão em pluma e mamona em bagas. Em fins de 1949, começou a operar a sua fábrica de óleos ${ }^{14}$. Pelos dados da revista, em 1975 o seu complexo industrial permitia o esmagamento de caroço de algodão, semente de oiticica ${ }^{15}$, amêndoas de babaçu ${ }^{16} \mathrm{e}$ tucum ${ }^{17}$, além de soja.

Acompanhando os locais de produção de sua matéria prima nas demais regiões, chegou a São Paulo e Paraná. A produção nestes dois estados foi significativa o suficiente para que, combinando o volume de mercadorias adquiridas, com sua industrialização, geração e comercialização de subprodutos, a Sanbra transferisse sua sede, em 1941, do Recife para São Paulo. De acordo com seus documentos, a matriz ficou em São Paulo, enquanto as filiais estavam distribuídas no Rio de Janeiro, Salvador, Recife, João Pessoa, Campina Grande, Natal e Fortaleza ${ }^{18}$.

Atuando no setor de grãos, a Sanbra foi ocupando o território nacional, atingindo toda a cadeia produtiva. Em relação à presença nacional, implantou atividades em 12 Estados, onde concentrava-se a maior parte da produção e do consumo. Dentre eles, merecem destaque São Paulo, com 31 atividades (32,6\%) e Paraná, com 23 (24,2\%), de um total de 95 funções exercidas em recebimento, produção e distribuição. Ambos foram favorecidos pelas três principais culturas na atuação da Sanbra: algodão, café e milho.

A Sanbra não fazia produção agrícola, mas estava presente nos demais estágios da produção e distribuição. Sua atuação, que atingia o total de 95 atividades, ficou assim distribuída, em 12 setores: i) 36 agências de compra de matéria prima; ii) 26 outras de beneficiamento inicial da produção; iii) 7 fábricas de óleos comestíveis e industriais; iv) 2 refinarias de óleos comestíveis; v) 2 fábricas de margarinas e gorduras; vi) 2 fábricas de sabão; vii) 1 fábrica de sorvetes; viii) 3 usinas de padronização de café; ix) 1 terminal graneleiro; x) 4 filiais e escritórios; xi) 10 unidades de vendas; xii) 1 fábrica de derivados de mamona (Relatório da Diretoria e Balanço Geral, 1980, p. 14 e revista Atualidades Sanbra, diversos números).

(14) Revista Atualidades Sanbra, Ano 8, v. 6, n. 48, p. 22, 1975.

(15) Oiticica é uma planta que pode atingir até 15 metros de altura, comum no nordeste brasileiro. Seus frutos podem ser utilizados para extração de corantes naturais e produção de biodiesel.

(16) Babaçu é uma planta da família das palmeiras, dotada de frutos com sementes oleaginosas e comestíveis das quais se extrai um óleo, empregado sobretudo na alimentação, remédios, além de ser alvo de pesquisas avançadas para a fabricação de biocombustíveis.

(17) Tucum é uma palmeira que atinge de 10 a 12 metros de altura. Cresce na Mata Atlântica, desde a Bahia até o Rio Grande do Sul. Produz pequenos cocos (com cerca de 2 centímetros de diâmetro) que fornecem óleo alimentício.

(18) Sanbra: Sociedade Algodoeira do Nordeste Brasileiro. Livro com o histórico da empresa sem data e sem páginas. Centro de Memória Bunge, São Paulo. 
A Tabela 5 evidencia a capacidade das maiores afiliadas de um BG mobilizarem e transferirem capital para outras empresas do Grupo, como apontado por Carney et al. (2011) e Khanna e Palepu (1997) e Morck (2010). No exemplo da Sanbra fica claro que, na década de 1980, ela manteve um alto volume de capital investido nas coligadas, entre US\$250 e US\$ 300 milhões. Em algumas das afiliadas manteve esta participação constante, exatamente com o mesmo percentual (Tintas Coral, 50,04\%; Imobiliária Olimpus, 21,18\%; Moinhos Riograndenses, 16,07\%). Por tratar-se, no entanto, de um grupo dinâmico, em outros setores houve desinvestimento, como nos casos das Maranhense e Sanbra Agropecuária Industrial. Também houve entrada em novas coligadas, como a Moinho Santista, a partir de 1982, com $2,65 \%$ do capital.

Tabela 5

Sanbra: Investimentos em empresas coligadas e controladas - 1980-1984 Participação no capital (em \%); Valor investido (em mil US\$ de abril de 2016)

\begin{tabular}{|c|c|c|c|c|c|c|}
\hline \multirow{2}{*}{$\begin{array}{l}\text { Anos/Cias. } \\
\text { Companhias }\end{array}$} & \multicolumn{2}{|c|}{1980} & \multicolumn{2}{|c|}{1982} & \multicolumn{2}{|c|}{1984} \\
\hline & $\begin{array}{c}\% \text { no } \\
\text { Capital }\end{array}$ & $\begin{array}{l}\text { Valor } \\
\text { invest. }\end{array}$ & $\begin{array}{c}\% \text { no } \\
\text { Capital }\end{array}$ & $\begin{array}{l}\text { Valor } \\
\text { invest. }\end{array}$ & $\begin{array}{c}\% \text { no } \\
\text { Capital }\end{array}$ & $\begin{array}{c}\text { Valor } \\
\text { investido }\end{array}$ \\
\hline $\begin{array}{l}\text { Cia. Bras. de Armazéns } \\
\text { Gerais }\end{array}$ & 47,77 & 22.790 & 10,07 & 4.850 & 10,07 & 4.226 \\
\hline Imobiliária Olimpus & 21,18 & 9.329 & 21,18 & 4.567 & 21,18 & 3.528 \\
\hline $\begin{array}{l}\text { Lubeca Administradora de } \\
\text { Bens }\end{array}$ & 31,96 & 65.370 & 41,52 & 104.876 & 41,52 & 87.902 \\
\hline $\begin{array}{l}\text { Maranhense Agropecuária e } \\
\text { Industrial }\end{array}$ & 69,39 & 3.222 & & 0 & & 0 \\
\hline $\begin{array}{l}\text { Sanbra Agropecuária e } \\
\text { industrial }\end{array}$ & 90,91 & 5.118 & & 0 & & 0 \\
\hline $\begin{array}{l}\text { Santista Ind. Têxtil do } \\
\text { Nordeste }\end{array}$ & 3,32 & 3.425 & 3,83 & 5.055 & 0,79 & 1.228 \\
\hline $\begin{array}{l}\text { S.A.Moinho Santista Ind. } \\
\text { Gerais }\end{array}$ & & 0 & 2,65 & 20.333 & 2,65 & 22.623 \\
\hline $\begin{array}{l}\text { S.A.Moinhos } \\
\text { Riograndenses }\end{array}$ & 16,07 & 39.401 & 16,08 & 35.762 & 16,06 & 39.760 \\
\hline Tintas Coral & 50,04 & 63.802 & 50,04 & 98.405 & 50,04 & 80.512 \\
\hline Toália Indústria Têxtil ${ }^{19}$ & & 0 & & 0 & & 0 \\
\hline Vera Cruz Seguradora & 21,86 & 15.692 & 9,28 & 18.922 & 9,28 & 15.742 \\
\hline Outras & & 5.385 & & 4.259 & & 2.242 \\
\hline Total & & 236.443 & & 305.370 & & 257.404 \\
\hline
\end{tabular}

Fonte: Elaboração dos autores a partir de Sanbra: Relatório da Diretoria e Balanço Geral, 1980, p. 18; 1982, p. 22; 1984, p. 21.

(19) A Toália S.A. Indústria Têxtil foi fundada em 1968 por empresários paraibanos e, em seguida, adquirida por outra subsidiária da Bunge, a Fábrica de Tecidos de Tatuapé-SP. Com nova tecnologia, a Toália passou a fazer, desde 1973, toalhas de rosto, banho e praia. Desta nova produção, "30\% destinava-se ao mercado internacional, sendo exportada para 30 países, entre eles, França, Alemanha, Itália, Suécia, Dinamarca, Noruega, Holanda, Suíça e Estados Unidos”. Em 1994 a Bunge vendeu a Fábrica Toália para a Artex (CMB, 2013, p. 17, 24). 
A Sanbra, além de garantir a participação da Bunge no agronegócio interno, foi a responsável por fazer da Bunge a terceira maior empresa exportadora em 1971, atrás somente da Cia. Vale do Rio Doce (minério de ferro) e do Instituto do Açúcar e Álcool (Cacex, 1971) ${ }^{20}$. Os grandes destaques da Sanbra ficaram por conta das exportações de algodão e óleo de mamona. Sobretudo, esta proeminência no mercado externo contradiz a tendência que os BG teriam em se fixar apenas no mercado interno de países emergentes, como aponta Guillén (2000) e Carney et al. $(2011)^{21}$.

Nos segmentos em que atuava, a Sanbra era líder, vice-líder ou ficava entre os cinco primeiros colocados em diversos produtos, como pode-se observar pela Tabela 6 .

Tabela 6

Sanbra - participação de seus produtos no mercado brasileiro - 1993

\begin{tabular}{|c|c|c|c|}
\hline Mercados e marcas & $\begin{array}{c}\text { Consumo } \\
\text { brasileiro (em } \\
\text { ton/ano) } \\
\end{array}$ & $\begin{array}{c}\text { Participação } \\
\text { Sanbra Alimentos }\end{array}$ & Posição \\
\hline \multicolumn{4}{|l|}{ Produtos de consumo } \\
\hline Margarinas domésticas (Delícia, Mila, Primor) & 350.000 & $31 \%$ & Vice-líder \\
\hline Maioneses (Maionegg's, Goodie) & 66.000 & $17 \%$ & $3^{\circ}$ \\
\hline Óleos enlatados (Salada, Primor) & 1.500 .000 & $4 \%$ & $5^{\circ}$ \\
\hline Sobremesas (Sol, Turma da Mônica) & 25.000 & $10 \%$ & $4^{\circ}$ \\
\hline Misturas (Sol) & 13.000 & $44 \%$ & Líder \\
\hline \multicolumn{4}{|l|}{ Ingredientes funcionais } \\
\hline $\begin{array}{l}\text { Proteínas isoladas e texturizadas (Samprosoy, } \\
\text { Proteimax, Maxten, Alipro) }\end{array}$ & 24.000 & $70 \%$ & Líder \\
\hline Lecitinas (Lecsam, Textrol) & 8.000 & $57 \%$ & Líder \\
\hline Gorduras industriais (Cukin Fry, Sancreme) & 155.000 & $50 \%$ & Líder \\
\hline \multicolumn{4}{|l|}{ Agro-Industrial } \\
\hline Soja (óleo e farelo) & 17.100 .000 & $5 \%$ & $4^{\circ}$ \\
\hline Algodão (caroço) & 500.000 & $20 \%$ & $2^{\circ}$ \\
\hline
\end{tabular}

Fonte: Elaboração dos autores a partir de Perfil (1994, p. 22).

A década de 1990 foi marcada pelo processo de reestruturação das empresas do Grupo Bunge: Sanbra, Samrig, Moinho Fluminense e Moinho Recife. Essas ações tinham como objetivo focar os investimentos da Bunge no setor de alimentos (Netz, 1993, Born, 2008). Tais mudanças influenciaram no número de funcionários que, no caso da Sanbra, diminuíram em

(20) Aliás, a documentação da empresa afirma que a Sanbra era "a maior exportadora privada do agronegócio", uma vez que a Vale e o Instituto do Açúcar e do Álcool, suas concorrentes e maiores exportadoras, eram estatais.

(21) Em 1990, as vendas externas da Sanbra representaram 30\% do seu faturamento líquido. As exportações da Sanbra foram de US\$180, 180, 173, 159 milhões entre os anos de 1990 e 1993 (Moinho Fluminense. Perfil, 1994, p. 21). 
cerca de 700 no início da década, o que elevou o faturamento de cada um, entre 1990 e 1993 de US\$ 117 mil para US\$ 132 mil (Perfil, 1994, p. 24).

As primeiras mudanças da reestruturação ocorreram quando a Sanbra incorporou a Samrig e alterou a sua denominação social para Sanbra Alimentos, conforme a Assembleia Geral de 27 de abril de 1994. Em 13 de setembro do mesmo ano, a Sanbra Alimentos alterou sua denominação social para Santista Alimentos que, após um mês, foi incorporada pelo Moinho Fluminense. Paralelamente, o Moinho Fluminense incorporou as participações no setor de alimentos do Moinho Recife e da Moinho Santista. A reestruturação societária iniciada neste ano reduziu o número de empresas da Bunge de 32 para 8 , aumentando seu capital (CMB, 2013, p. 26). Através desta reestruturação, a Sanbra deixou de existir enquanto empresa individual e suas atividades foram incorporadas pela Bunge Brasil.

\section{Santista Têxtil: de uma necessidade a uma diversificação empresarial}

O setor têxtil da Bunge no Brasil nasceu vinculado ao Moinho Santista que, por sua vez, foi fundado em 30 de novembro de 1905. De acordo com os Estatutos, sua finalidade era "a compra e moagem de trigo e outros cereais nacionais e estrangeiros, compra e venda de farinha e farelos, assim como a fabricação de massas e congêneres”.

Ainda em 1907, por causa da demanda de sacaria para embalar a farinha, dirigentes do Moinho Santista lançaram a ideia de montar uma indústria têxtil. Foi só em 1924, no entanto, que os acionistas resolveram investir no setor e sua diretoria adquiriu o primeiro maquinário para fiação e tecelagem. Conforme descrição de Humberg (2004, p. 54) 22 uma pequena seção de sacaria começou a funcionar no dia 25 de agosto de 1925, na Avenida Celso Garcia, no bairro do Tatuapé-SP, produzindo parte da sacaria necessária para o moinho.

Adentrando ao setor têxtil, a Bunge promoveu, no dia 29 de outubro de 1929, na sede do Moinho Santista, a Assembleia Constitutiva da Fábrica de Tecidos Tatuapé. Conforme publicação do Diário Oficial de 7 de novembro de 1929, a primeira diretoria da fábrica ficou assim constituída: Presidente Alfredo Hirsch (executivo da Bunge no Brasil); Secretário João Ugliengo. Diretores: Jorge Oster (executivo da Bunge no Brasil), Pablo Pels e Vincenzo Scandura. Segundo a Tabela 7, o capital inicial era de dez mil contos de réis, divididos em 50.000 ações de 200 mil réis cada uma, sendo que 98,6\% destas ações pertenciam às empresas do Grupo Bunge (Moinho Fluminense, Moinho Santista, Moinhos Riograndenses e Grandes Moinhos do Brasil).

(22) Os autores seguiram, nesta parte do artigo, o texto de Humberg (1994). No entanto, consultaram a documentação original, no Centro de Memória Bunge, em São Paulo, para complementar e tornar mais detalhada a descrição da firma. 
Tabela 7

Subscritores de ações da Fábrica de Tecidos Tatuapé - 1929

\begin{tabular}{|c|c|}
\hline Subscritores & Número de ações \\
\hline Moinho Fluminense S.A. & 23.000 \\
\hline S.A. Moinho Santista & 22.800 \\
\hline Moinhos Riograndenses S.A. & 1.750 \\
\hline Grandes Moinhos do Brasil S.A. & 1.750 \\
\hline União Mercantil Brasileira S.A. & 500 \\
\hline João Ugliengo & 100 \\
\hline Vincenzo Scandura & 50 \\
\hline João Baptista Della Casa & 40 \\
\hline Armando Fachada & 10 \\
\hline Total & 50.000 \\
\hline
\end{tabular}

Dessa forma, tanto do ponto de vista do controle acionário quanto dos cargos diretivos, o Grupo Bunge era quem comandava a Fábrica Tatuapé e, com ela, diversificava sua atuação no mercado brasileiro (Fernández Pérez; Lluch; Fernández Pérez; Casanova, 2012; Khanna; Yafeh, 2007). Ademais, a Fábrica Tatuapé - como no caso da Sanbra e Tintas Coral representava novamente a transferência de expertise do mercado argentino, pois a Bunge criara em 1926 a Grafa S. A. - que se tornaria a maior empresa têxtil daquele país - e, pouco depois, replicava o empreendimento no mesmo setor dentro do mercado brasileiro, valendo-se dos capitais e das afiliadas (Keister, 1998).

Nos primeiros anos, o destaque da Fábrica de Tatuapé ${ }^{23}$ era a produção de tecido para sacaria de algodão cru. Além de abastecer o Moinho Santista, a fábrica fornecia sacaria para as usinas de açúcar do Estado de São Paulo e para os grandes moinhos de trigo de todo o país, do Recife ao Rio Grande do Sul.

O sucesso da Fábrica de Tecidos Tatuapé estimulou novos investimentos no setor. Em 1934 começou a construção de uma grande fiação de lã no Belenzinho-SP, a S.A. Moinho Santista Indústrias Gerais - Lanifício. Construída numa chácara, a Fiação Santista ocupava área de $7.000 \mathrm{~m}^{2}$. A nova planta era dividida em dois setores, a Seção Lã e a de Algodão, fazendo fios para terceiros e malharia (Humberg, 2004, p. 66).

O Lanifício, conhecido como Fábrica do Belenzinho, foi programado para trabalhar com lã brasileira, produzida no Rio Grande do Sul. Com uma equipe inicial de 650 empregados, a Belenzinho foi a primeira grande fábrica do Brasil a produzir, a partir de 1935, fios de lã de forma sistemática e de qualidade comparada aos fios franceses.

(23) Como um empreendimento da S.A. Moinho Santista, a Fábrica de Tecidos Tatuapé e as outras unidades têxteis que surgiriam em seguida, tornaram-se conhecidas, desde os anos 1930, com a denominação genérica de Santista Têxtil, para se diferenciar das outras atividades do Moinho. 
O Grupo Santista, para manter sua participação e atingir novos segmentos, executou, em 1947, um projeto de reestruturação de seu parque têxtil. Vendeu duas fábricas antigas - de Santo André, a Ipiranguinha e a do bairro paulistano do Cambuci, cuja fiação de lã cardada e tecelagem foram transferidas para a Fábrica do Belenzinho -. Esta foi ampliada, em 1948, com a construção de um prédio de quatro andares e novos equipamentos, comprados por uma comissão de técnicos na Itália, Alemanha, França e Estados Unidos. Além disso, outra fábrica foi projetada para ser construída em Osasco.

A Fábrica de Osasco, que foi inaugurada em 1949, produzia apenas tecido para sacaria, mas em 1951 a Santista diversificou, buscando novos consumidores, entrando na fabricação de lençóis, cuja ideia veio da Argentina, onde a Grafa, maior e mais antiga indústria têxtil, pertencente à Bunge, já fornecia tal produto. Em 1952, os lençóis Ouro e Prata, de solteiro e casal, já estavam nas melhores lojas de São Paulo (Humberg, 2004, p. 81).

Após a inauguração da Fábrica de Osasco, a Fábrica Celso foi inteiramente modernizada. Juntas, as duas passaram a industrializar 18 toneladas de algodão por ano, produzindo anualmente 5 milhões e 600 mil lençóis; 18,5 milhões de metros de brins; 1 milhão de metros de tecidos industriais e 7 milhões de metros de tecidos para exportação. Em 1958, a África do Sul foi o primeiro país a receber a pioneira exportação de cretone Ouro Santista, com largura de 2,29m, produzido na Fábrica de Osasco, denotando novamente - como no caso da Sanbra - a característica do Grupo Bunge em não se restringir ao mercado nacional (Humberg, 2004, p. 82).

Na segunda metade da década de 1960, o Brasil entrou em nova fase de crescimento, na qual o setor têxtil se expandiu e consolidou. Interessada em participar do processo de industrialização do Nordeste, incentivado pelo Governo Federal, através da Superintendência de Desenvolvimento do Nordeste - SUDENE, a Santista iniciou em 1967, perto de Recife-PE a implantação de sua primeira fábrica fora de São Paulo: a Sitene - Santista Indústria Têxtil do Nordeste.

Contando com apoio financeiro do Banco do Nordeste do Brasil e com incentivos fiscais da SUDENE para executar o projeto, a fábrica foi inaugurada em 1970, dotada de Fiação, Tecelagem e Acabamento, com $54.821 \mathrm{~m}^{2}$ de área construída, num terreno de $200 \mathrm{mil}$ $\mathrm{m}^{2}$. Além do maquinário levado de São Paulo, a Sitene recebeu equipamentos da Suíça, Alemanha, Inglaterra e Estados Unidos. Foram cerca de cinco mil caixas contendo máquinas e componentes para fiação, tecelagem, acabamento, compressores de frio e um laboratório completo para controle de produção (Humberg, 2004, p. 106).

Em meados dos anos 1970, a Sitene foi duplicada num projeto aprovado pela SUDENE, com novo investimento, capacitando-a a produzir de 400 a 500 toneladas mensais de fios de algodão, além de fios de poliéster, e industrializar 25 milhões de metros quadrados anuais de tecidos. Esta integração entre BG e o governo brasileiro, no afã de uma maior industrialização e exportação de manufaturas, gerava um cenário favorável à Bunge no mercado brasileiro, como aponta Carney et al. (2011), Schneider (2010) e Guillén (2000). 
O know-how desenvolvido na Fábrica de Osasco foi transferido à nova unidade e, em 12 de outubro de 1973, a Santista Têxtil inaugurou a Toalia para produzir quatro milhões de toalhas de rosto, banho e praia e $700 \mathrm{mil} \mathrm{m}^{2}$ de tecidos felpudos por ano. A fábrica foi a segunda da Santista no Nordeste, três anos depois da inauguração da Sitene, e criou 416 empregos. O empreendimento, como a Sitene, contou com o apoio da Sudene e do Banco do Nordeste. "A Toalia recebeu investimento direto de 70 milhões de cruzeiros do Grupo Santista e mais 11,4 milhões de incentivos fiscais da SUDENE" (Humberg, 2004, p. 110).

Em relação ao destino, 30\% de toda a produção de felpudos da Toalia destinaram-se ao mercado internacional, sendo exportada para 30 países, entre eles, França, Alemanha, Itália, Suécia, Dinamarca, Noruega, Holanda, Suíça e Estados Unidos.

Em 1975, a Divisão Têxtil do Grupo Santista tinha seis fábricas. Fez novos investimentos em Americana (estado de São Paulo) e, em 1976 começou a operar uma segunda unidade, com um total de 40 mil fusos e 504 teares. No ano, a unidade, com área construída de 50 mil $\mathrm{m}^{2}$ e investimento acumulado de CR $\$ 500$ milhões, produziu 22 milhões de metros lineares de tecido (Humberg, 2004, p. 122).

Em 1979, a Fábrica Celso comemorou 50 anos, instalada numa área de mais de 70 mil $\mathrm{m}^{2}$ e $41 \mathrm{mil} \mathrm{m}^{2}$ de área construída. Nela trabalhavam 1.120 funcionários. No ano seguinte ao cinquentenário, a Santista decidiu ampliar a produção de 2,5 milhões de metros mensais para cinco milhões, instalando novos equipamentos em Americana. Os 1.900 funcionários da unidade passaram a produzir o legítimo índigo blue Santista, destinado à fabricação de jeans.

Esméril Stocco Vieira que, em 1979, assumira a gerência geral da Santista Têxtil, aproveitou essa situação para adquirir, em 1981, uma fábrica pronta, a Brasital, tradicional indústria de Salto-SP. Situada num terreno de 132 mil m², tinha 1.400 funcionários e produzia fios e tecidos de puro-algodão. Era uma nova ampliação do parque industrial da Santista, que já exportava para 40 países $^{24}$.

Outra análise do grupo Santista pode ser feita em relação à rentabilidade de suas empresas. No caso das vendas, percebe-se que houve um destaque na rentabilidade, comparando as empresas do grupo com a média nacional, que foi de 3,5\%, sobretudo do Moinho Santista, que atingiu 32,4\%. Análise semelhante pode ser feita sobre a rentabilidade do patrimônio onde, apenas duas firmas, a Toália e a Serrana, ficaram abaixo da média nacional de 14,9\%, com destaque para a Fábrica Tatuapé, cuja rentabilidade atingiu mais que o dobro da média do país, ou seja, 35,8\%. Estes dados corroboram os apontamentos de Carney et al (2011) sobre o desempenho favorável das afiliadas dos BG em países como Brasil e México, ao compensar os vazios institucionais (Tabela 13).

(24) As exportações brasileiras de produtos têxteis continuaram a crescer e, em 1980, atingiram US\$ 916 milhões, subindo para US\$ 1 bilhão em 1985. Os produtos exportados provinham de 28.770 estabelecimentos de indústria têxtil e vestuário, calçados e artefatos, dos quais 5.570 eram fábricas de fios e tecidos (Censo Industrial, IBGE, 1985). 
Tabela 13

Grupo Santista - Rentabilidade das empresas - 1981

\begin{tabular}{l|c|c|c|c}
\hline Empresas & $\begin{array}{c}\text { Vendas (em Cr\$ } \\
\text { bilhões) }\end{array}$ & $\begin{array}{c}\text { Lucro Líquido } \\
\text { (em Cr\$ bilhões) }\end{array}$ & $\begin{array}{c}\text { Rentabilidade } \\
\text { das vendas (em } \\
\%)\end{array}$ & $\begin{array}{c}\text { Rentabilidade do } \\
\text { patrimônio } \\
\text { líquido (em \%) }\end{array}$ \\
\hline $\begin{array}{l}\text { S.A. Moinho Santista. Ind. } \\
\text { Gerais }\end{array}$ & 11,4 & 3,7 & 32,4 & 23,4 \\
\hline $\begin{array}{l}\text { Fábrica de Tecidos Tatuapé } \\
\text { S.A. }\end{array}$ & 20,0 & 3,0 & 15,2 & 35,8 \\
\hline $\begin{array}{l}\text { Sitene - Santista Ind. Têxtil } \\
\text { do Nordeste }\end{array}$ & 3,2 & 0,4 & 12,7 & 16,3 \\
\hline Toália S.A. Ind. Têxtil & 1,9 & 0,1 & 7,6 & 12,9 \\
\hline $\begin{array}{l}\text { Quimbrasil. Química Ind. } \\
\text { Brasileira }\end{array}$ & 17,4 & 1,4 & 8,1 & 25,5 \\
\hline Serrana S.A. de Mineração & 4,0 & 0,5 & 12,8 & 13,2 \\
\hline Média Brasileira em 1980 & - & - & 3,5 & 14,9 \\
\hline
\end{tabular}

Fonte: Elaboração dos autores a partir de Negócios em EXAME, 2 dez. 1981. Revista Têxtil, p. 37, 1981.

Em relação aos produtos têxteis a Santista, além da diversificação em vários setores, com marcas fortes e tradicionais, produtos diversificados, mantinha um market-share próximo a $30 \%$ do mercado nacional.

Tabela 14

Grupo Santista no setor têxtil. Produção e market-share - 1981

\begin{tabular}{l|c|c|c}
\hline Produtos & Marcas & Produção anual & $\begin{array}{c}\text { Participação no } \\
\text { mercado }\end{array}$ \\
\hline Lençóis & $\begin{array}{c}\text { Santista, Kamacolor, } \\
\text { Paladium, Royal, Super Prata }\end{array}$ & 5 milhões de unidades & $20 \%$ \\
\hline Toalhas de banho & Santista & 8 milhões de unidades & $20 \%$ \\
\hline Brins & $\begin{array}{c}\text { Santista, Indigo Santista, } \\
\text { Indigo Stretch Santista, } \\
\text { Terbrim, Solasol, Tapé }\end{array}$ & $\begin{array}{c}100 \text { milhões de } \\
\text { metros }\end{array}$ & $30 \%$ \\
\hline Casimiras & Santista, Classic, Opus & 5 milhões de metros & $30 \%$ \\
\hline Linhas para tricô e crochê & $\begin{array}{c}\text { Keamor, Cinderella, Pluma, } \\
\text { Maxi }\end{array}$ & 675 toneladas & $38 \%$ \\
\hline Lã (uso individual) & Santista & 500 toneladas & $10 \%$ \\
\hline
\end{tabular}

Fonte: Elaboração dos autores a partir de Negócios em EXAME, 2 dez. 1981. Revista Têxtil, p. 34, 1981.

Em fevereiro de 1987, o grupo retomou seus investimentos no Nordeste. Próximo de Aracaju, iniciaram as obras de construção da Sanser - Santista Indústria Têxtil de Sergipe, fábrica destinada ao acabamento de tecidos de algodão e mistos, com 270 funcionários. Na construção foram investidos US\$ 42 milhões. Sua outra fábrica, a Sitene, após duas décadas, em 1988, tinha um faturamento anual de US\$ 72 milhões, vendendo fios, tecidos para uniformes, brins e poliéster, alcançando uma rentabilidade de $43,9 \%$, enquanto a média do setor têxtil era de 9,1\% (Humberg, 2004, p. 144). 
A Santista Têxtil adquiriu, em setembro de 1988, a Karibê S.A. Indústria e Comércio ${ }^{25}$, uma das maiores fornecedoras de fios de fibras longas no mercado brasileiro, instalada em Santa Isabel-SP. Negociada com Heinrich Cytrynowicz, um de seus donos, a compra foi efetuada por US\$28 milhões e manteve 1.553 funcionários $^{26}$.

No final da década de 1980, a Santista contava com 15 mil funcionários distribuídos em oito fábricas, em quatro estados. São Paulo: Celso Garcia (Tatuapé), Osasco, Belenzinho, Americana e Brasital; Pernambuco: sitene; Paraíba: Toalia; e Sergipe: Sanser. Exportava US\$ 110 milhões em produtos têxteis, sendo a líder do setor nas vendas ao exterior, respondia por $52 \%$ de todo faturamento do Moinho Santista e faturava US\$ 500 milhões/ano.

\section{Bunge Brasil e a reestruturação na década de 1990}

Segundo Colpan e Hikino (2016), os anos 1980 marcariam adversidades para os BG em diversos países, como reflexo, por exemplo, da dificuldade em formar quadros gerenciais aptos a comandarem negócios tão diversos. Ademais, a queda do modelo stateled industrialization abriu a possibilidade de uma maior concorrência entre as empresas nacionais e estrangeiras, em meio ao contexto da globalização econômica. Como resposta, vários BG passaram por processos de reestruturação que se basearam na concentração de suas atividades no que era considerado o core business. No caso da Bunge na Argentina, de uma empresa que atuava até no ramo petroquímico nos anos 1980, o que se viu foi a retomada do eixo agrícola (produção e exportação de grãos e fertilizantes agrícolas) (Barbero, 2011; Barbero; Lluch, 2015).

No Brasil, cujo modelo de industrialização induzida pelo Estado colapsou na década de 1980, segundo Aldrighi e Postali (2010), a reestruturação também se tornou uma diretriz aos BG. A Bunge Brasil, após caracterizar-se como grupo econômico extremamente diversificado, passou por transformações no final do século XX. Nos três primeiros anos da década de 1990, "perdeu US\$ 176 milhões e suas receitas diminuíram em um terço" (Netz, 1993, p. 22). Estes problemas seriam devido ao controle financeiro frágil e ineficiente, capital de giro insuficiente, estrutura com altos custos e formulação estratégica pobre, advindos de uma estrutura superdimensionada pela diversificação excessiva, gerando uma fragilidade

(25) A Karibê começou como empresa familiar em 1947, na região de Wuertemberg, na Alemanha, fundada pelos irmãos Artur, Leopold, Gustav e Heinrich Cytrynowicz e por Josef Dorf. Começou com três funcionários e, seis meses depois, já empregava 30. Em 1951 a fábrica foi transferida para a região de Ulm e, em 1954, para o Brasil, no bairro do Tatuapé-SP. Em 1959 aumentou sua fábrica para $10 \mathrm{mil} \mathrm{m}^{2}$, empregando 700 trabalhadores. No final de 1968 a fábrica tinha $30 \mathrm{mil} \mathrm{m}^{2}$ e empregava 1.700 funcionários. No ano seguinte, mudou para Santa Isabel onde construiu uma planta industrial de $107 \mathrm{mil} \mathrm{m}^{2}$ (Humberg, 2004, p. 147).

(26) No ano em que a Santista adquiriu a Karibê, a indústria têxtil brasileira empregava cerca de 1,1 milhão de pessoas. O setor se concentrou no Sudeste, onde trabalhavam 759 mil funcionários, sendo 578 mil (66,1\%) no estado de São Paulo (Associação Brasileira da Indústria Têxtil - Abit, 1988). A entidade informava que havia 4.648 fábricas têxteis no país, das quais 2.728 localizavam-se em São Paulo. Apenas 230 empregavam mais de 500 operários, enquanto $41 \%$ eram pequenas, médias e microempresas. 
exposta em um cenário de maior concorrência da globalização econômica (Serra; Ferreira; Contrigiane, 2009).

Neste contexto, a Bunge mundial contratou a consultoria McKinsey para uma proposta de reestruturação (CMB, 2013; O'Donnell, 2015, Born, 2008). Terminados os estudos e a proposta, a nova Bunge Brasil foi organizada em cinco áreas de atuação, cada qual com uma empresa líder (conforme a Tabela 1 no início do texto): Tintas Coral (Tintas), Tatuapé (Têxtil), Sanbra/Samrig (óleo de soja e margarinas), Santista Alimentos (trigo e derivados) e Serrana (Cimento e Fosfatados).

Para comandar a reestruturação a Bunge substituiu Juan Born III por Octavio Caraballo na presidência mundial do grupo e substituiu Juan Born por um "executivo de mercado", Ludwig Schmitt-Rhaden, que trabalhava na Degussa Corporation mundial (Born, 2008; O’Donnell, 2015; Calais, 2018) ${ }^{27}$. Este, ao iniciar seus trabalhos, encontrou uma empresa que estava entre os maiores grupos do país. "À época com 27.000 empregados, cerca de 40 fábricas espalhadas por dez Estados, suas receitas de US\$ 2 bilhões eram suficientes para colocá-la em $219^{\circ}$ lugar entre as 500 maiores corporações listas pela revista Fortune, caso fosse baseada nos Estados Unidos" (Netz, 1993, p. 24).

Em todas as áreas de atuação tinha posição de destaque. Em alimentos, suas empresas garantiam-lhe o terceiro lugar, logo após Nestlé e Sadia. No ramo têxtil, estava entre os três maiores, ao lado da Vicunha e da Alpargatas. Em tintas, a Coral só perdia para a Glassurit, do grupo Basf. Nas exportações do agronegócio a Sanbra ocupava o primeiro lugar.

Quando Schmitt-Rhaden assumiu o cargo deparou-se com uma espécie de hieróglifo contábil. O grupo controlava 127 empresas (Calais, 2017) com razões sociais diferentes. "Havia quatro holdings, que também exerciam funções operacionais. Três delas, Moinho Santista, Moinho Fluminense e Moinho Recife, eram companhias de capital aberto. A quarta, Sanbra, era de capital fechado. Em diferentes proporções, cada uma delas detinha participações acionárias nas demais empresas do grupo" (Netz, 1993, p. 25).

Em três anos de reestruturação, as 127 empresas foram reduzidas a 30, agrupadas em cinco áreas (Tabela 16). "Cerca de 7.000 funcionários foram demitidos, entre eles 400 executivos de primeiro e segundo níveis, representando uma redução de gastos de US\$150 milhões" (Netz, 1993, p. 26). A partir de então, sob comando executivo de diretores contratados, a Bunge Brasil intensificou suas atividades no core business: agronegócio e alimentos.

(27) Desta data em diante, os executivos das diversas empresas passaram a ser contratados no mercado. As famílias acionistas continuaram controlando e mantendo a presidência do Conselho de Administração e formaram um "Conselho Familiar, cujas reuniões acontecem sempre na Europa" (Calais, 2018). 


\section{Considerações finais}

A Bunge Brasil consolidou-se como grupo econômico na segunda metade do século $\mathrm{XX}$ porque tomou diversas medidas: diversificou atividades e investiu em diferentes setores até chegar a ter 127 empresas independentes. Neste leque de atuação, entrou em vários setores da economia, aumentou permanentemente sua capacidade instalada, ocupou o território nacional, exportou e, algumas de suas coligadas, transformaram-se em outras multinacionais (Tintas Coral que instalou planta industrial na Bolívia), aproveitou os incentivos fiscais do governo ao implantar-se e expandir-se no Nordeste.

O texto estudou esta expansão e consolidação de um grupo econômico analisando quatro empresas líderes de diferentes setores: Moinho Fluminense, para trigo e derivados; Tintas Coral, em tintas e vernizes; Sanbra atuando no agronegócio e exportações e; Santista Têxtil no setor de tecidos, fitas, brins e jeans. Estas foram escolhidas tanto pela sua representatividade, classificadas como grandes conglomerados industriais, mas também por representarem a diversidade de ramos de atuação em que a Bunge entrou no Brasil e que a consolidou como grupo econômico.

Para Born (2008) a Bunge Brasil transformou-se num grupo econômico porque "foi aplicando o excedente de recursos conseguidos através das exportações argentinas e brasileiras", até construir um grupo de 127 empresas (Calais, 2017). Portanto, os recursos gerados na exportação permitiram investimentos numa gama de outras atividades. Depois, com o tempo e a experiência, algumas companhias líderes em diversos setores transformaram-se, elas mesmas, em outros grupos econômicos, diversificando atividades e constituindo outras associadas e coligadas, como foi o caso das quatro empresas analisadas neste texto.

A consolidação do grupo econômico veio também através da expansão de atividades no mesmo ramo, aumentando sua capacidade produtiva e, como consequência, o market-share. Um exemplo desta atuação aconteceu com o Moinho Fluminense no biênio 1971-72. Após o aumento de sua capacidade instalada, transformou-se no maior moinho do Brasil, nos aspectos de moagem e vendas de derivados de trigo.

Analisando as atividades da área de trigo, outra ação da Bunge que a consolidou como grupo econômico foi a compra de concorrentes. Iniciou associando-se ao Moinho Santista em 1905 para depois adquirir o Moinho Fluminense (1914), o Moinho Recife (1914), a Samrig, com várias plantas industriais no Rio Grande do Sul (1929). Nas décadas de 1930-40, a Samrig constituiu moinhos em cinco cidades: Erechim, Passo Fundo, Guaporé, Cruz Alta, Uruguaiana e incorporou o Moinho Joinville, em Santa Catarina. As aquisições contribuíram tanto para o aumento da capacidade instalada como para atender a demanda regional e ocupar o território nacional.

A consolidação do grupo econômico se deu também pelo acesso ao crédito via Bolsa de Valores. O Moinho Santista abriu o capital em 1969, passando a contar com recursos de terceiros no processo de crescimento e diversificação. Além disso beneficiou-se de seus 
próprios bancos e/ou daqueles em que investia recursos. Por fim, por tratar-se de uma multinacional presente em mais de 40 países de todos os continentes, o acesso ao crédito era facilitado pela rede de contato com o sistema financeiro internacional.

A participação das empresas da Bunge em outros setores contribuiu para consolidá-la como grupo econômico. O Moinho Fluminense investiu no setor têxtil; em margarinas, óleos e gorduras vegetais; tintas e produtos químicos; administração e leasing; bancos e seguros. O Moinho Santista investiu, em 1989, nos seguintes setores: i) alimentício, com quatro moinhos; ii) imobiliário; iii) têxtil, com seis fábricas; iv) seguros, com duas empresas; v) informática, com duas firmas; vi) financeiro, através do Banco Santista de Investimentos; vii) mineroquímico, com seis atividades e, por fim; viii) a Fundação Moinho Santista. Comportamento semelhante tiveram outras firmas do grupo, como o Moinho Recife, a Samrig, a Tintas Coral, a Santista Têxtil, a Sanbra, entre outras.

A Bunge consolidou-se como grupo econômico porque, além de atender o mercado nacional, também exportava. As exportações da Sanbra foram de US\$ 180 milhões em 1991. A Tintas Coral exportava para 20 países em 1994 (além de instalar uma planta industrial na Bolívia). No setor têxtil, 30\% da produção da Toalia era exportada para 30 países, entre eles, França, Alemanha, Itália, Suécia, Dinamarca, Noruega, Holanda, Suíça e Estados Unidos. No final da década de 1980, a Santista Têxtil exportava US\$ 110 milhões em produtos têxteis e era líder do setor nas vendas ao exterior.

A consolidação de grupo econômico aparecia na relação mantida entre as diversas coligadas. O Moinho Fluminense investiu, em 1974, Cr\$241,3 milhões em empresas coligadas de seis setores diferentes: margarina, óleo e gorduras vegetais; tintas e produtos químicos; administração e leasing; bancos e seguros; diversas. Em 1976 investiu capital e tinha ações em 16 firmas coligadas. A Tintas Coral do Nordeste "está coligada à sua congênere Tintas Coral de São Paulo, tanto juridicamente, através da participação acionária, como tecnicamente, pela assistência técnica prestada". A Sanbra tinha 12 empresas coligadas em 1984, nas quais investiu US\$257,4 milhões.

A diversificação de produtos aparece em várias das empresas líderes da Bunge, sendo outra característica dos grupos econômicos. A Tintas Coral produzia, em repintura automotiva: acabamentos, complementos e thinners; para a indústria: tintas para madeira, litografia, manutenção, tinta em pó; produtos intermediários: emulsões e resinas; outros: tintas artísticas, para cerâmica e couro. A Sanbra chegou a ter 95 diferentes atividades, em 12 setores, assim distribuídas: i) 36 agências de compra de matéria prima; ii) 26 outras de beneficiamento inicial da produção; iii) 7 fábricas de óleos comestíveis e industriais; iv) 2 refinarias de óleos comestíveis; v) 2 fábricas de margarinas e gorduras; vi) 2 fábricas de sabão; vii) 1 fábrica de sorvetes; viii) 3 usinas de padronização de café; ix) 1 terminal graneleiro; x) 4 filiais e escritórios; xi) 10 unidades de vendas; xii) 1 fábrica de derivados de mamona.

A concepção de grupos econômicos leva em consideração as relações entre as empresas e os governos. No caso da Bunge, soube adaptar-se às condições da região e 
Armando Dalla Costa, Gustavo Pereira da Silva, Alexandre Macchione Saes

aproveitar os incentivos fiscais. Como exemplo, pode-se mencionar a Toalia, que recebeu investimento de Cr\$ 70 milhões do Grupo Santista e Cr\$11,4 milhões de incentivos da SUDENE.

No que tange à ocupação do território nacional, outra característica dos grupos econômicos, a Bunge o fez através de diversas de suas empresas. A Santista Alimentos, em 1993, tinha nove plantas industriais em oito Estados para atuar com trigo e derivados. No final da década de 1980 a Santista Têxtil tinha 8 fábricas em 4 Estados. A Tintas Coral, em 1986, mantinha 19 escritórios de vendas em 14 Estados. Atuando no setor de grãos, a Sanbra foi ocupando o território nacional, atingindo toda a cadeia produtiva. Implantou atividades em 12 Estados, onde concentrava-se a maior parte da produção e do consumo de algodão, café e milho. Dentre eles, merecem destaque São Paulo, com 31 atividades (32,6\%) e Paraná, com 23 $(24,2 \%)$, de um total de 95 funções exercidas em recebimento, produção, industrialização e distribuição.

\section{Referências bibliográficas}

\section{Fontes primárias}

ABIT - Associação Brasileira da Indústria Têxtil. Relatório. São Paulo, 1988.

ATA da Assembleia Geral Extraordinária da Sociedade Anonyma Moinho Fluminense. Rio de Janeiro, 28 maio 1914.

ATA da Assembleia Geral da Fundação da Fábrica de Tecidos Tatuapé S.A. Diário Oficial, 7 nov. 1929.

ATA da Reunião do Conselho Administrativo do Moinho Fluminense S.A. Rio de Janeiro, 28 maio 1946.

BORN, Jorge. President, Bomagra S.A. Interviewed by Andrea Lluch, Research Fellow, Harvard Business School. August 21, 2008 in Buenos Aires, Argentina.

BUNGE. 100 Anos: uma história brasileira. São Paulo: Centro de Memória Bunge, 2016. 187p.

CEM anos de história do Moinho Fluminense. São Paulo: Centro de Memória Bunge, 1987. $36 \mathrm{p}$.

BUNG Paints. Onde estamos. São Paulo: Centro de Memória Bunge, 1994.

BUNGE. Relatório de Sustentabilidade. 2013 a 2017.

CACEX. Carteira de Comércio Exterior do Banco do Brasil. 1971.

CALAIS, Cláudia. Entrevista concedida aos autores pela diretora do Centro de Memória Bunge. São Paulo, 16 jan. 2018.

CALAIS, Cláudia. Apresentação do Centro de Memória Bunge. Palestra durante o curso de História de Empresas na FEA/USP, entre os dias 23 e 27 de outubro, 2017. 
CMB - Centro de Memória Bunge. Histórico. Tintas Coral S.A. São Paulo: Centro de Memória Bunge, 1986.

CMB - Centro de Memória Bunge. Histórico do Grupo Bunge. São Paulo: CMB, 2010. 55p.

CMB - Centro de Memória Bunge. Cem Anos de História do Moinho Fluminense. São Paulo: CMB, 2016. 36p.

CONTRATO da Sociedade Comanditária Denominada "Moinho Fluminense", sob a razão social de "Gianelli \& Cia.", firmado em 17 de fevereiro, 1887.

CONTRATO Social celebrado entre Carlos Gianelli e Francisco de P. Mayrink. Rio de Janeiro, 1887.

DECRETO n. 9.776 de 25 de Agosto de 1887. Autoriza a funccionar a Sociedade em Commandita por acções Moinho Fluminense, 10p. Assinado pela Princeza Imperial Regente, 1887.

DIÁRIO Oficial. São Paulo, 7 nov. 1929.

ESTATUTOS da Sociedade Anônima Moinho Fluminense. Rio de Janeiro: 14 out. 1989.

ESTATUTOS da “Sociedade Anonyma Moinho Fluminense". Rio de Janeiro, 28 maio 1914.

GARANTIA. Banco de Investimentos Garantia S.A. Moinho Fluminense. Relatório de empresa. Reestruturação cria gigante de alimentos com grande potencial. 13 jun. 1994. 30p.

A BUNGE: Nossa história. Disponível em: http://www.bunge.com.br/Bunge/Nossa Historia.aspx. Acesso em: 11 jan. 2016.

IBGE -Instituto Brasileiro de Geografia e Estatística. Censo Industrial. Diretoria de Pesquisas, Departamento de Indústria. Rio de Janeiro: IBGE, 1985.

MOINHO Fluminense S.A. Relatório Anual. 1927 a 1957.

MOINHO Fluminense S.A. Indústrias Gerais. Relatório Anual. 1984/85.

MOINHO Fluminense S.A. Indústrias Gerais (1887 - 100 Anos - 1997). Relatório da Administração. 1997.

MOINHO Fluminense S.A. Indústrias Gerais. Relatório da Administração. 1998.

MOINHO Fluminense S.A. Acionistas. Rio de Janeiro, 1929.

MOINHO Fluminense S.A. Diretoria. 1889 a 1959.

MOINHO Fluminense S.A. O que nós somos. Texto com síntese dos principais momentos da história da empresa. Rio de Janeiro, jun. 1976. 6p.

MOINHO Fluminense S.A. Indústrias Gerais. Relatório Anual. 1968 a 1988.

MOINHO Fluminense S.A. Indústrias Gerais. Perfil. Jun. 1994. 
Armando Dalla Costa, Gustavo Pereira da Silva, Alexandre Macchione Saes

MOINHO Santista. Assembleia Constitutiva da Fábrica de Tecidos Tatuapé. São Paulo: CMB, 29 out. 1929.

MOINHO Santista e Associadas. Ano X, n. 35, jun.

MOINHO Santista. Relatório da Diretoria. 1961.

MOINHO Santista. Estatutos da Sociedade Anônima Moinho Santista. São Paulo: Centro de Memória Bunge, 1905-1908.

NETZ, C. O mistério começa a ser desvendado. Depois de décadas na sombra, um dos mais poderosos e secretos grupos do mundo - o Bunge - decide mostrar o rosto. Exame, São Paulo, ano 25, ed. 547, n. 26, p. 19-26, 22 dez. 1993.

O MOAGEIRO. Publicação interna do Moinho Fluminense S.A. Indústrias Gerais. Ano XI, n. 127, maio/jun. 1986 (consulta a diversos números).

REVISTA Atualidades Sanbra, Ano 8, n. 48, v. 6, 1975.

REVISTA Bolsa. Valor de mercado das Empresas Abertas, n. 829, 31 jan. 1988.

S.A. Moinho Santista. Relatório da Diretoria. 1961.

SANBRA. Ata da Assembleia Geral de 27 de abril, 1994.

SANBRA - Sociedade Algodoeira do Nordeste Brasileiro (s.d; s.p). Licro com o Histórico da Empresa. São Paulo: Centro de Memória Bunge.

SANBRA 50 anos. Separata de Atualidades Sanbra, n. 31, ano 6, jan/fev. História do Algodão. Publicada pela Coordenação de Relações Públicas da Sanbra, 1973.

SANBRA. Relatório da Diretoria e Balanço Geral. 1972-1982.

SANTÊXTIL. Publicação Mensal destinada aos Funcionários do Setor Têxtil da Revista Têxtil. Santista comemora 80 anos voltada para o futuro. São Paulo, 1981.

SANTÊXTIL. Publicação Mensal destinada aos funcionários do Setor Têxtil da Tintas Coral do Nordeste S.A. Projeto da Fábrica. Recife, Pernambuco, 1989. Documento consultado no Centro de Memória Bunge. São Paulo. 219p.

TINTAS Coral. Relatório de Diretoria e Balanço Geral. São Paulo: Centro de Memória Bunge, $1975 / 76$.

TINTAS Coral. Tintas Coral do Nordeste S.A. São Paulo: Centro de Memória Bunge, 1965.

TINTAS Coral. Relatório da Administração. São Paulo: Centro de Memória Bunge, 1992.

TINTAS Coral. Tintas Coral: 40 anos de qualidade total. São Paulo: Centro de Memória Bunge, 1994. 
Bunge Brasil (1956 a 1994): consolidação de um grupo

\section{Outras referências bibliográficas}

ALDRIGHI, D. M.; POSTALI, F. A. S. Business groups in Brazil. In: COLPAN, A. M.; HIKINO, T.; LINCOLN, J. R. The Oxford handbook of business groups. Oxford: Oxford University Press, 2010.

BARBERO, M. I. Los grupos económicos en la Argentina en una perspectiva de largo plazo (siglos XIX y XX). In: JONES, G.; LLUCH, A. El impacto histórico de la globalización en Argentina y Chile: empresas y empresarios. Buenos Aires: Temas, 2011.

BARBERO, M. I.; LLUCH, A. El capitalismo familiar en Argentina: modelos y dinámicas en el largo plazo. In: FAMILIAS empresarias y grandes empresas familiares en América Latina y España. Bilbao: Fundación BBVA, 2015.

BARROS, G. O desenvolvimento do setor siderúrgico brasileiro entre 1900 e 1940: crescimento e substituição de importações. Estud. Econ., São Paulo, v. 45, n. 1, p. 153-183, mar. 2015.

BELINI, C. El Grupo Bunge y la política económica del primer peronismo, 1943-1952. Latin American Research Review, v. 41, n. 1, p. 27-50, Feb. 2006.

BONELLI, R. As estratégias dos grandes grupos industriais brasileiros nos anos 90. Brasília: Ipea, jul. 1998. (Texto para Discussão, n. 569).

BULL, B. Diversified business groups and the transnationalisation of the Salvadorean economy. Journal of Latin American Studies, v. 45, n. 2, p. 265-295, 2013.

CARNEY M.; GEDAJLOVIC E. R.; HEUGENS P. P.; VAN E. M.; VAN O. J. H. Business group affiliation, performance, context, and strategy: a meta-analysis. Academy of Management Journal, 54, p. 437-460, 2011.

CHANDLER, A. D. Strategy and structure: chapters in the history of the industrial enterprise. Cambridge: The MIT Press, 1962.

COLPAN, A. M.; HIKINO, T. Diversified business groups in the West: history and theory (October 26, 2017). Forthcoming as Chapter 2 in Colpan and Hikino. 2017. (Ed.). Business Groups in the West: origins, evolution and resilience. Oxford: Oxford University Press, 2017. (Harvard Business School Research Paper Series, n. 17-035). Available at SSRN: https://ssrn.com/abstract=2860028.

COLPAN, A. M.; HIKINO, T. Foundations of business groups: towards an integrated framework. In: COLPAN, A. M.; HIKINO, T.; LINCOLN, J. R. (Ed.). The Oxford handbook of business groups. University of Oxford: Oxford University Press, 2010. p. 15-66.

CUESTA, M.; NEWLAND, C. Rentabilidad, evolución patrimonial y diversificación en tres grandes compañías argentinas, 1926-1955. América Latina en la Historia Económica, [s.1.], v. 23, n. 2, p. 204-228, 2016. 
Armando Dalla Costa, Gustavo Pereira da Silva, Alexandre Macchione Saes

DALlA COSTA, A. J.; DRUMOND, C. E.; LAS HERAS, J. M. Empresas y grupos empresariales brasileños en perspectiva histórica. In: FERNÁNDEZ PÉREZ, P.; LLUCH, A. Familias empresarias y grandes empresas familiares en América Latina y España. Bilbao: Fundación BBVA, 2015.

DALLA COSTA, A. J. D.; SILVA, G. P. Bunge and his first fiftieth anniversary in Brazil (1905-1955): The construction of an economic group. Investigaciones de Historia Economica, v. 14, p. 199-209, 2018.

DELIOS, A.; MA, X. Diversification strategy and Business Groups. In: In: COLPAN, A. M.; HIKINO, T.; LINCOLN, J. R. (Ed.). The Oxford handbook of business groups. Oxford: Oxford University Press, 2010.

FAUSTO, B.; DEVOTO, F. Brasil e Argentina: um ensaio de história comparada (1850-2002). São Paulo: Ed. 34, 2004.

FERNÁNDEZ PÉREZ, P.; CASANOVA, L. Algunas claves de la longevidad de las grandes empresas familiares brasileñas. Apuntes, Universidad del Pacífico, v. 39, n. 70, p. 273-300, $1^{\circ}$ semestre 2012.

FERNÁNDEZ PÉREZ, P.; LLUCH, A. Introducción. In: FERNÁNDEZ PÉREZ, P.; LLUCH, A. Familias empresarias y grandes empresas familiares en América Latina y España. Bilbao: Fundación BBVA, 2015.

FRANCO, E. A. La Bunge \& Born: un conglomerado multinacional. Revista de la Facultad de Ciencias Económicas, Lima, p. 111-119, 1997.

FRANCO, G. H. B. e LAGO, L.A.C. O processo econômico. SCHWARCZ, L. M. (Ed.). A abertura para o mundo: 1889-1930. Rio de Janeiro: Objetiva, 2012.

GLADE, W. A América Latina e a economia internacional, 1870-1914. In: BETHELL, L. História da América Latina, v. IV: de 1870 a 1930. São Paulo: EDUSP, 2009.

GONÇALVES, R. Grupos econômicos: uma análise conceitual e teórica. Revista Brasileira de Economia, Rio de Janeiro, v. 45, n. 4, p. 491-518, out./dez., 1991.

GRANOVETTER, M. Coase revisited: business groups in the modern economy. Industrial and Corporate Change, v. 4, n. 1, p. 93-130, 1995.

GRANOVETTER, M. Business groups and social organization. In: SMELSER, N.; SWEDBERG R. (Ed.). The handbook of economic sociology. 2. ed. Princeton: Princeton University Press, 2005. p. 429-450.

GREEN, R.; LAURENT, C. El poder de Bung \& Born. 2. ed. Buenos Aires: Nueva Información, 1989. Edição original: Bunge \& Born. Puissance et secret dans l'agroalimentaire. Paris: Edition Publisud, 1985. 
GUILLÉN, M. F. Business groups in emerging economies: a resource-based view. Academy of Management Journal, v. 43, n. 3, p. 362-380, 2000.

HOLMES JR., M.; ROBERT, E. H.; KIM, H.; WAN, W. P.; HOLCOMB, T. R. International strategy and business groups: a review and future research agenda, Journal of World Business, v. 53, n. 2, p. 134-150, 2018.

HUMBERG, M. E. Santista Têxtil. Uma história de inovações. 75 anos. São Paulo: CLA Comunicações/Pancron Indústria Gráfica, 2004.

JONES, G.; COLPAN, A. M. Business groups in historical perspectives. In: COLPAN, A. M.; HIKINO, T.; LINCOLN, J. R. (Ed.). The Oxford handbook of business groups. Oxford: Oxford University Press, 2010.

KEISTER, L. A. Engineering growth: business groups structure and firm performance in China's transition economy. American Journal of Sociology, 104, p. 404-440, 1998.

KHANNA, T.; YAFEH, Y. Business groups in emerging markets: paragons or parasites? Journal of Economic Literature, v. 45, n. 2, p. 331-372, 2007.

KHANNA, T.; PALEPU, K. Why focused strategies may be wrong for emerging markets. Harvard Business Review, v. 75, n. 4, p. 41-51, 1997.

KOURY, S. E. C. A desconsideração da personalidade jurídica (Disregard Doctrine) e os grupos de empresa. 3. ed. Rio de Janeiro: Forense, 2011.

LEFF, N. H. El espíritu de empresa y la organización industrial en los países menos desarrolalados: los grupos. El Trimestre Económico, v. XLI, 3, Jul./Sept. 1974.

MINELLA, A. C. Grupos financeiros no Brasil: um perfil econômico e sociopolítico dos maiores credores privados. In: WORKSHOP EMPRESA, EMPRESÁRIOS E SOCIEDADE, 5, Porto Alegre, PUC-RS, 2-5 maio 2006.

MORCK, R. The riddle of great pyramids. In: The Oxford Handbook of business groups. In: COLPAN, A. M.; HIKINO, T.; LINCOLN, J. R. (Ed.). The Oxford handbook of business groups. Oxford: Oxford University Press, 2010.

MORGAN, D. Los traficantes de granos. La historia secreta del pulpo mundial de los cereales: Cargill, Bunge, André, Continental y Louis Dreyfus. 2. ed. Buenos Aires: Editorial Abril, 1984. Tradução de Floreal Mazía y Luis Coco, by Merchants of Grain, 1979.

NETZ, C. O mistério começa a ser desvendado. Depois de décadas na sombra, um dos mais poderosos e secretos grupos do mundo - o Bunge - decide mostrar o rosto. Exame, São Paulo, ano 25, ed. 547, n. 26, p. 19-26, 22 dez. 1993.

OCAMPO, J. A.; BÉRTOLA, L. The economic development of Latin America since the Independence. Oxford: Oxford University Press, 2012. 
Armando Dalla Costa, Gustavo Pereira da Silva, Alexandre Macchione Saes

OCAMPO, J. A.; ROS, J. Shifting paradigms in Latin America's Economic Development. In: OCAMPO, J. A.; ROS, J. (Ed.). The Oxford handbook of Latin American economics. University of Oxford: Oxford University Press, 2011.

PENROSE, E. A teoria do crescimento da firma. Campinas: Editora da Unicamp, 2006.

ROCHA, M. A. M. Grupos econômicos e capital financeiro: uma história recente do grande capital brasileiro. 2013. Tese (Doutorado)-Universidade Estadual de Campinas, Campinas, 2013.

SERRA, F.; FERREIRA, M.; CONTRIGIANE, E. Turbulência nos anos 1990: o "turnaround" da Bunge. Revista Portuguesa e Brasileira de Gestão, Lisboa, v. 8, n. 1, p. 76-88, mar. 2009.

SCHNEIDER, B. R. Business groups and the State: the politics of expansion, restructuring and collapse. In: COLPAN, A. M.; HIKINO, T.; LINCOLN, J. R. (Ed.). The Oxford Handbook of business groups. Oxford: Oxford University Press, 2010.

SCHVARZER, J. Bunge y Born. Crecimiento y diversificación de un grupo económico. Buenos Aires: CISEA-GEL, 1989.

SILVA, G. P.; DALLA COSTA, A. A Bunge e sua instalação no mercado brasileiro (18181905): as estratégias de um grupo econômico no capitalismo monopolista. História e-história. Online, v. 1, p. 1-25, 2014.

SUZIGAN, W. Indústria brasileira: origem e desenvolvimento. São Paulo: Ed. Hucitec/Ed. Unicamp, 2000.

SUZIGAN, W.; SZMRECSÁNYI, T. Os investimentos estrangeiros no início da industrialização do Brasil. In: SILVA, S.; SZMRECSÁNYI, T. (Org.). História econômica da Primeira República. São Paulo: Hucitec/ABPHE/ Editora da USP/ Imprensa Oficial, 2002.

SZMRECSÁNYI, T. Contribuição a análise do planejamento da agroindústria canavieira do Brasil. Tese (Doutorado)-Instituto de Economia, Unicamp, Campinas, 1976.

TRINDADE, C. M. Grupos econômicos argentinos: expansão e estratégias nos anos 2000. Dissertação (Mestrado)-Instituto de Economia, Unicamp, Campinas, 2017.

VILLELA, A. A. O desenvolvimento econômico no Brasil pré-1945. In: FERREIRA, P. et al. Desenvolvimento econômico: uma perspectiva brasileira. Rio de Janeiro: Elsevier, 2013.

VILLELA, A. A. The 19th and Early 20th Centuries. In: AMANN, E.; AZZONI, C.; BAER, W. The Oxford handbook of Brazilian economy. New York: Oxford University Press, 2018.

YAPRAK, A.; KARADEMIR, B. The internationalization of emerging market business groups: an integrated literatura review. International Marketing Review, 27, p. 245-262, 2010.

YILDIRIM-ÖKTEM, O.; SELEKLER-GOKSEN, N. Internationalization of family business groups: content analysis of the literature and a synthesis model. European Journal of Family Business, v. 8, n. 1, p. 45-68, 2018. 